\title{
Problems of effective use of new constructions of electric power installations, based on renewable energy resources
}

\author{
Mikhail Balzannikov ${ }^{1}$, Sergey Evdokimov ${ }^{1, *}$, and Yulia Galitskova ${ }^{1}$ \\ ${ }^{1}$ Samara State Technical University, Institute of Architecture and Civil Engineering, 194 \\ Molodogvardeyskaya St.,443001, Samara, Russia
}

\begin{abstract}
Nowadays hydraulic and power installations can be defined as power installations that are well-designed in terms of construction and technology and working on renewable energy resources (RER). However wide use of such power stations is interfered by their low performance in comparison with thermal stations, using organic fuel. The purpose of the conducted research in this article is - search of ways to increase the competitiveness of power stations, using RER, in comparison with traditional power stations. In order to achieve the specified purpose the authors solved the following tasks: they analyzed and developed new constructive solutions of the power stations using RER; they developed the power-economic viability method for the choice of key parameters of the power stations working on RER. The researchers also gained the set objectives, using theoretical and experimental methods of calculation connected with physical modeling, the theoretical analysis and use of an economic case of the made decisions. Thus, carried-out analysis of designs of the power stations, based on RER allowed to develop a method of efficiency enhancement of these installations and to solve a problem of wider use of power stations as a part of the installations working on RER. The provided technical solutions of power stations that give the chance to develop new suggestions for improvement of designs of power stations, based on RER and to promote development of recommendations about their competitive recovery. As a result it will allow to create conditions for production of the effective national power stations, based on RER, and cumulative scientific and technical potential, that can be used for further development of nonconventional wind power and hydropower both in Russia, and abroad.
\end{abstract}

\section{Introduction}

All sources of electric power can be divided into two groups: non-renewable and renewable. The share of the first of them in balance of energy consumption accounts for 85$87 \%$. The renewable sources (RS) exist in the environment constantly and their potential is high. However, they make up only $14-12 \%$ of energy consumption $[1,2]$. Such ratio has

*Corresponding author: sali5@mail.ru 
developed historically under the influence of a number of objective reasons of power development. However at the present stage such situation can be hardly called rational.

Important contribution to the solution of the above-mentioned ecological problems is involvement of RER in fuel and energy balance. Recommendations of international forums about problems of the environment, decisions of conferences of various levels, focused on the solution of environmental problems, and also governmental orders of our country, particularly - regulations of "new energy policy of Russia" about forming ecologically favorable structure of fuel and energy balance of Russia and its separate economic regions based on environmentally friendly power sources can prove this contribution.

Nowadays hydraulic energy and wind flow energy is most widely used as the most well-known RERs. [3, 4]. The power stations, using hydraulic energy of hydroelectric power station (hydroelectric power station) in particular differ in a number of important benefits: such as low cost value of electricity production, high efficiency and maneuverability of aggregates, high automation, small service personnel. The urgent trend of energy provision and improvement of ecology is involvement of other RERs in power supply, in particular, solar, wind, oceanic (tidal, wave, thermal, energy of a current, salinity, etc.), geothermal, energies of biomass and others.

Hydraulic energy and energy of wind flows is the most widely used among other RERs. Modern wind power units (WPU) use wind of a ground layer in the atmosphere. The analysis of wind conditions of the area is necessary for detection of feasibility of their use and construction. The annual average long-term speed of wind is one of the main indicators of these conditions at a preliminary stage of detection of prospects of WPU. This value should be $6 \mathrm{~m} / \mathrm{s}$ for WPU construction. In this case installation will be effective. Many regions with WPU have a sufficient wind potential for use on the territory of our country, for example such territories as the North Sea coasts, a coastal strip of Arctic and Pacific oceans, South of the Primorsk Territory and others [5-7].

However wide use of power stations working, based on RERs is interfered by their low cost efficiency in comparison with thermal stations, using organic fuel. Such situation developed because ecological factors and a situation of the specific region in which use of installations, based on RER, is possible in case of determination of efficiency and competitiveness of power stations, aren't fully considered. The carried-out analysis of the papers [8-11] devoted to technical and economic indicators of power stations of this kind revealed the major factors that characterize competitiveness of power stations, based on RER. These are: capital investments per unit of capacity of installation; cost value of electricity production; durability and reliability of work; charge for the energy supply; availability of rather reasonably-priced materials for production of the power station; use of progressive methods and technologies for production of its elements, installation and operation of installation; ecological purity; satisfaction of the consumers' demands and social orientation; the volume of necessary lump sum investments; indicators of territory's transfer, etc.

Research of academicians shows that [12-14] constructive decisions of separate elements, and of all power station in general, besides the factors noted above, produce great influence on efficiency and competitiveness of power stations, based on RER. In particular, a form and the number of blades of the driving wheel of the power station, the device of regulation of frequency of rotation of the driving wheel and torque transmission on the generator, form and conditions of a flow on the way to the driving wheel (runner), etc.

Thus, at this stage of development of scientific and technical progress, in questions of use of renewable energy resources, further search of ways of competitive recovery of power stations, based on RER, in comparison with traditional power stations, is necessary. It is possible due to the solution of the following tasks: development and analysis of new constructive solutions of the power stations using RER; development of power-economic 
viability allowing to choose key parameters of the power stations, based on RER. The authors achieved the objectives successfully and the results of the research, that reflect the purpose of this paper, are given below.

\section{Materials and Methods}

Designs of power stations and separate elements of power stations, based on RER constantly develop, upgrade and improve. It is caused by the following reasons [15].

The first reason is that elements of hydropower stations (hydroelectric power station), storage plants (pumped storage power plant), pump stations (PS), wind power installations (WPI) and other power stations, as well as any technical systems, develop in the direction of elimination of the shortcomings revealed earlier. At the same time new constructive decisions help to decrease losses of energy and increase the total efficiency. In some cases constructive developments are directed to reduction in cost of installations due to decrease in a material capacity or replacement of expensive materials with less valuable, possessing new properties, and improvement of constructive forms, reduction of amounts of works or increase of technological effectiveness of works with these elements.

The second reason is that the quality standards for considered devices, as well as power stations in general, change. This tendency has been widely spread recently. Requirements to the environmental protection have risen, reliability and safety of their operation have improved, working conditions of service personnel have considerably upgraded. Consequently, the designs of devices change and alternations are constantly made.

The third reason is that previously unknown materials with necessary new properties, new technologies, and also other achievements of national and foreign science and technology are at the disposal of engineering firms and the organizations.

These reasons also cause development of power stations, based on RER, and their elements. Works on enhancement of designs of hydropower stations, namely hydraulic turbines of hydroelectric power station and pumped storage power plant are particularly effective as they are very large elements, significantly influencing energy indicators and cost, and, therefore, efficiency and reliability of operation of all power stations in general become considerably high.

The design of the hydraulic turbine, developed by a group of authors of Architectural and construction institute of Samara state technical university [16], given in fig. 1 can serve as an example of design improvement.

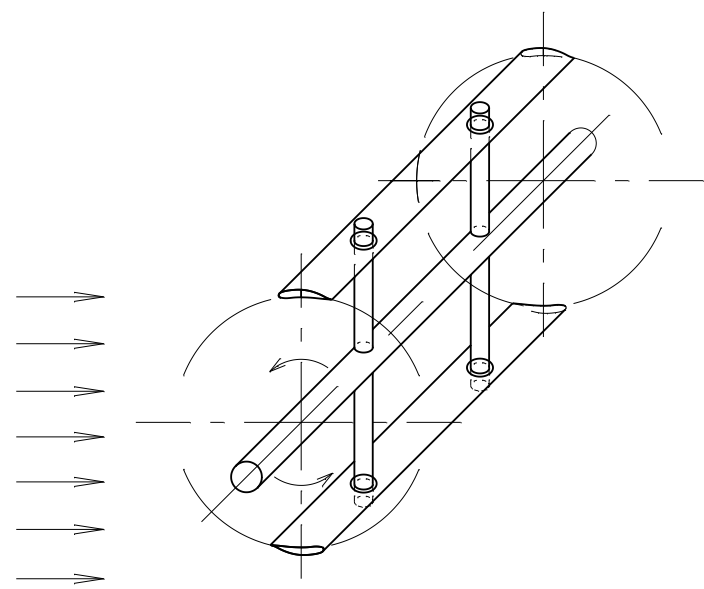

Fig. 1. General outline of hydraulic turbine construction 
The offered design can effectively be applied in the hydraulic turbines of orthogonal type placed in water-wheel installations with small pressures for the competitiveness recovery, reliability and durability of work. In such hydraulic turbines the blades have considerable length and identical aerodynamic profile. Thus, it is reasonable to use not fullheight blades in the design, but blades consisting of pressure head and back surfaces between which the connecting plates for construction stiffening are placed.

The positive effect of the use of the invention is revealed in the following. The material capacity of the hydraulic turbine of orthogonal type due to the blades with cavities and such separate elements as pressure head and back for providing an aerodynamic profile considerably decreases in the offered device. Cavities significantly reduce the consumption of high-quality expensive metal of which blades are made. Besides, use of separate pressure head and back elements in the form of curvilinear surfaces will allow using material of identical thickness, for example, the rolling metal sheet that will significantly reduce labor input of production of the blade. The above-mentioned factors will allow reducing considerably the cost of the hydraulic turbines with blades of an aerodynamic profile used in water-wheel installations, and, therefore, to raise their competitiveness, cost efficiency, to provide reliability and durability of work.

It is essential to increase efficiency of energy use of sea currents, to ensure effective and reliable functioning of power generation at the industrial level for the purpose of reduction of an environmental impact of traditional power stations of combined heat and power plant, hydroelectric power station, atomic power station, it is possible due to use of new design of the hydrogenerator of sea currents, developed by the group of authors of Architectural and construction institute of Samara state technical university [17]. The design of the hydrogenerator of sea currents is shown in fig. 2.

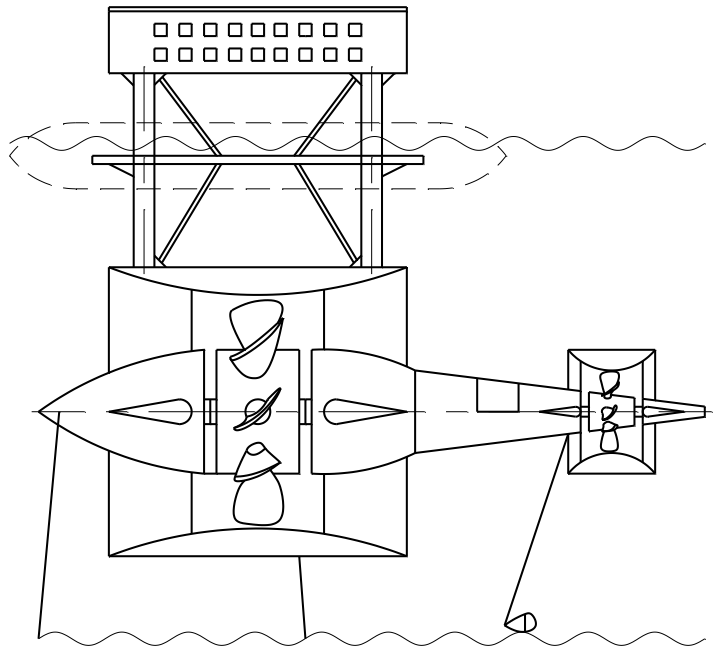

Fig. 2. General outline of hydro-generator of sea currents/

The technical result in case of implementation of the offered design is achieved due to increase in modular capacity, efficiency and reliability of the hydro-generator. It is achieved by essentially new design of the hydro-generator which consists of the underwater body with a confusor, the diffuser, a zone of high-speed pressure between them, system of fixation on a seabed. The basis of the whole design are two underwater spindle-shaped bodies, parallely connected as a twin hull craft by a binding unit. In a forward part of each body the ring of additional hydrodynamic dispersal of a water flow representing the 
cylinder from the inside having a convex surface from the outer side is mounted. The accelerating ring on the case is established on poles, forward and back, horizontal and vertical. Poles in section have a hydrodynamic profile, lobbies work as an additional confusor, back - as the diffuser that strengthens effect of hydrodynamic dispersal of a flow. The bladed water-wheel with a horizontal axis of rotation which is coaxially connected to the electric generator by split sleeves through the raising planetary reducer is located on the high-speed site between forward and back poles. The axis of rotation of the turbine coincides with the direction of a sea current. The benefit of this design is that the accepted scheme of parallel connection of underwater spindle-shaped bodies among themselves looks as the twin hull craft, in a nasal part - a binding unit, in fodder - the horizontal stabilizer, allows creating the reliable bearing, having good stability with high potential of floatation ability.

The construction is capable to take up all loadings in any directions and plane surfaces, to balance and neutralize all arising tension and the rotary moments, and availability of the accelerating block allows getting the energy of a water flow with maximum efficiency. The accepted concept allows creating a reliable aggregate of big capacity capable to maintain extreme loadings and to become an alternative energy source.

The following example of the power station, based on RER, is a construction of a rotary wind-power unit with full-revolving blades, which is also developed by a group of academicians of Architectural and construction institute of Samara state technical university [18]. The proposed constructive solution is focused on the task - to increase reliability of operation of all power station that will allow to apply wind-power units in zones with an average wind potential more widely, for example in the central regions of the country. The general outline of a design of a rotary wind-power unit is shown in fig. 3 .

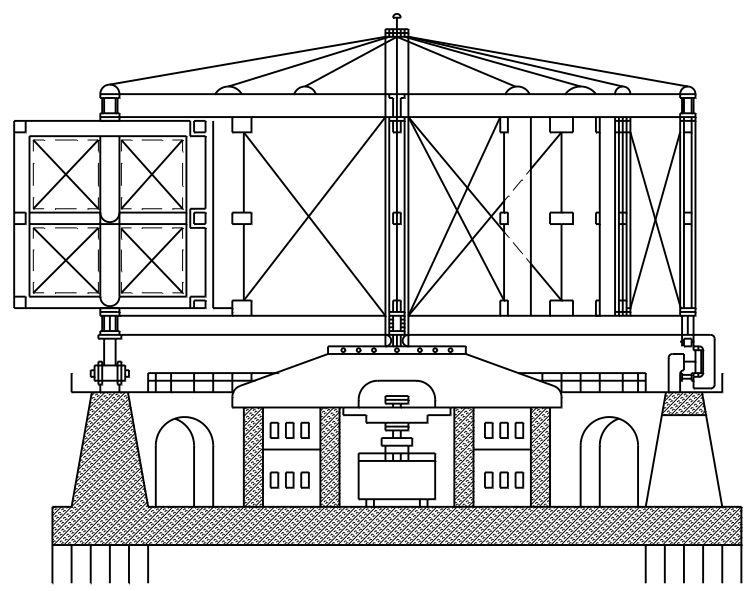

Fig. 3. General outline of the construction of a rotary wind-power unit.

The technical result which will be reached after implementation of the invention is reflected in increase of modular power and efficiency of a wind power unit, increase in reliability of work of a rotary wind-power unit with full-rotary blades, and also reduction of a material capacity and cost of the power station design.

The positive effect of this invention is reflected in the following. Considering that power consumption of wind in usual conditions is rather low, in order to get industrial electric power it is necessary to create the device that have big surfaces of the working planes that increases its overall dimensions and weight. In practical operation extreme wind force in storm values aren't subject to use, but installation in the prepared condition will resist these impacts. For this purpose in the offered design of a wind power unit the bearing 
points are divided: into peripheral ring, taking up the bulk of installation and wind, and the central bearing point, taking up the weight of the central part of installation, being the concentrator of energy and the sending device to the main generator. Such concept allows creating the aggregate of big capacity capable to take up extreme loadings and to provide increase in reliability of work of the whole design.

Evident illustration of the third reason which is the cornerstone of improvement of designs of power stations, based on RER, is a wind-power unit construction with stream concentrator, made of light and cheap elastic materials [19]. The scheme is shown in fig. 4. Light material is fixed on the diffuser framework, consisting of rigid rings and longitudinal slides. Such construction of a diffuser will allow to provide an automatic turn of the concentrator under the influence of wind to the direction of a wind stream due to wind resistance .

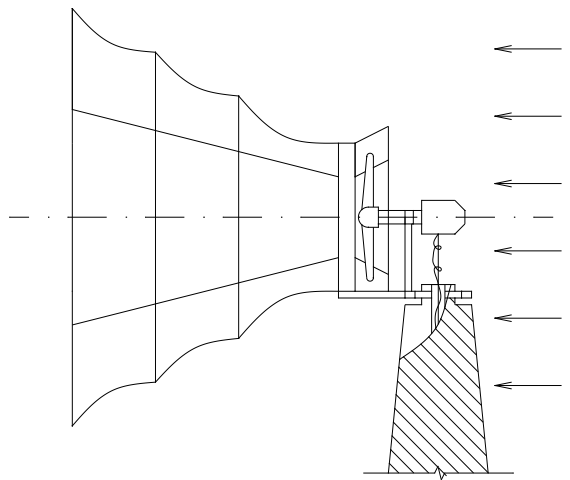

Fig. 4. Construction of wind-power unit with flow concentrator, made of light material.

It must be kept in mind that such concentrator can fail, for example, in case of hurricane wind speeds. However, it is possible to replace it with the new concentrator without considerable costs. All wind-power units constructions are very mobile, that will allow to use them in emergency areas, where mobile power sources are required.

In order to improve wind-power units by approximation of its massive parts to a posting axis it is offered to provide it with the ring joint, support platform, a supporting ring and the rod. The support platform is located horizontally and rigidly connected to the ring joint, and the supporting ring is set vertically and rigidly connected to a support platform, and the rod is placed vertically on a support platform, on which the wind wheel and the generator are set. Approximation of massive parts of a wind-power unit to an axis, reduces the torque and the bending impact on a vertical diaphragm, and, therefore, will reduce the breakage of a wind-power unit and will increase reliability of its operation.

Thus, new developed technical solutions on designs of the most important elements of the power stations, based on RER allow to increase the overall performance of basic elements and power stations in general significantly, and also to provide considerable competitive recovery of the power stations, based on RER. The available margin allows to conclude about the prospects of further improvements.

\section{Results}

The choice of parameters of elements of designs and constructions of the power stations using energy of currents is of great importance for further effective use and competitive recovery of power stations, based on RER. Cost effectiveness analysis of any energy object needs to be carried out together with identification of the ecological and social 
acceptability. These questions should be considered with special attention during the design of the power stations working from RER as they are characterized essentially by various types of ecological impact in relation to traditional power stations.

The authors of this paper developed the technique of a power-economic viability of key parameters of new constructive solutions of the power stations, based on RER [20, 21].

The developed methodology accepted the following predicate as a target function [9]:

$$
E E_{\Sigma}=\sum_{i=1}^{I} \sum_{t=1}^{T} \bar{P}+\sum_{j=1}^{Q} \sum_{t=1}^{T} \bar{D}
$$

In which $E E_{\Sigma}$ - power-economic effect; $I$ - a number of expenditures related to the cost of power installations, based on wind-power units; $Q$ - profit elements related to the cost of power installations, based on wind-power units; $t$ - considered time period; $T$ - design-base time period $\sum_{i=1}^{I} \sum_{t=1}^{T} \bar{P}$ - capital value of all expenditures during the design-base time period; $\sum_{j=1}^{Q} \sum_{t=1}^{T} \bar{D}$ - capital value of all profit elements during the design-base time period.

Identifying the parameters of power installation, based on RER, as vector X, the equation (1) can be rewritten as:

$$
E E_{\Sigma}\left(x_{1}, x_{2}, \ldots x_{n}\right)=E E_{\Sigma}(\mathrm{X}) \rightarrow \max
$$

The $x_{i}$ parameters of power installation are restricted.

Firstly, these are the restrictions of the interval change in design-base time period:

$$
x_{i}^{\min } \leq x_{i} \leq x_{i}^{\max } .
$$

These are, for example, restrictions on the length of the concentrator of wind-power unit flow. (fig. 4), on the diameter of the runner of a hydraulic turbine (fig. 1), on the length of confusor and diffuser section of hydro-generator of sea currents (Fig. 2) and e.t.c.

Secondly, the area of joint parameter variations:

$$
\varphi_{k}(X) \leq 0, k=1,2, \ldots, K .
$$

These limitations come from the requirements to the characteristics of various working modes of power installations, based on RER.

Thus, the task of the choice of optimized parameters of the power station consists in satisfaction of criterion (1) or (2) in case of restrictions (3) and (4).

Let's consider the application of a method of a power-economic viability of key parameters for a wind power unit with flow concentrator in more details (fig. 4). The first criterion sum should include (1):

$$
\sum_{i=1}^{I} \sum_{t=1}^{T} \bar{P}=C_{A}+C_{K}+C_{E A}+C_{E K}
$$

in which $C_{A}$ - unit cost, including its delivery and assembling; $C_{K}$ - cost of a concentrator, including its delivery and assembling; $C_{E A}$ - annual exploitation costs of a unit; $C_{E K}-$ annual exploitation costs of a flow concentrator. The cost of a unit depends on many parameters, among which its capacity which is the most important. However, manufacturing companies of units can already quite definitely provide data on the cost of 
the produced units at a preliminary stage. Costs for the flow concentrator device can be generally determined as:

$$
C_{K}=\phi\left(D_{p k} ; \alpha ; \beta ; L\right)
$$

in which $\mathrm{D}_{\mathrm{pk}}$ - diameter of the runner of a power unit, $\alpha$ - angle of input confusor part of a unit concentrator, $\beta$ - angle of diffusing airfoil in output part, $L$ - the length of a concentrator.

The second criterion sum includes:

$$
\sum_{j=1}^{Q} \sum_{t=1}^{T} \bar{D}=D_{E}+D_{D},
$$

in which $D_{E}$ - annual profit of power realization, $D_{D}$ - other types of profit, for example, by conversion of securities, depreciation accounting and e.t.c.

$$
D_{D}=m \cdot E
$$

in which $m$ - charge on $1 \mathrm{kWhe}$; - electricity output:

$$
\ni=\int N d t
$$

in which $N$ - basic power parameter of a unit - the capacity which is calculated as:

$$
N=C_{N} * \eta_{M} * \eta_{\text {Эл }} * W * \rho * \frac{V^{3}}{2}
$$

in which $C_{N}$ - power efficiency of the flow (water, air), depending on the type, form and geometric characteristics of a runner in a power unit; $\eta_{M}-$ mechanical efficiency; $\eta_{\text {эл }}-$ electric efficiency; $W$ - surface area for accumulation of a power current; $\rho$ - flow density; $V$ - flow speed in the zone of a runner.

If the type and the main sizes of the unit are defined or set in advance (in particular, the sizes of the runner, the number of blades, etc.), then, as appears from the above, its power will be defined by flow speed in a zone of the runner. The flow speed in a zone of the runner is defined by stream speed $V_{0}$ outside the unit, and as the pilot studies show, depends on geometrical parameters of the concentrator of a flow:

$$
V_{P}=\phi\left(V_{0} ; \alpha ; \beta ; L\right)
$$

in which $\alpha$ и $\beta$ - flared angles in the output confusor and output diffuser part of a unit concentrator, $L$ - length of the concentrator. This dependence is achieved as result of experimental data analysis.

The key varied parameters are the concentrator sizes - length $L$ and angles $\alpha$ and $\beta$ at the stage of optimization of geometrical parameters of the concentrator of a flow for the known or set unit. The combination of the varied sizes of the concentrator gives $m$ options for the solution of a problem of the choice of the optimized sizes of the concentrator:

$$
k=1,2, \ldots \ldots, m,
$$

in which $k$ - the order number of considered alternatives.

On the one hand, each option corresponds to the cost characteristics of production of the concentrator of a flow, on the other hand - the speeds of an air stream gained 
experimentally and presented in the form of mathematical relations in the zone of a wind wheel. We choose optimized geometrical parameters of the power station after consideration of the most viable options and definition of the discounted costs of expenditures and profit elements for the design-base time period, using criterion (1) or (2).

\section{Discussion}

The research of technical and economic indicators of the power stations, based on RER, conducted by authors allowed developing a method for the choice of elements and designs and by that to solve a problem of wider use of complex energy stations as a part of the installations, based on RER. The analysis of technical solutions of power stations gives the chance to develop new suggestions for improvement of designs of the power stations, based on RER and to promote recommendations about their competitive recovery. This research will allow to create conditions for production of effective national power stations, based on RER, and cumulative scientific and technical potential that can be used for further development of nonconventional wind power and small hydropower, as well as in Russia and abroad.

Thus, developed methodological recommendations will allow providing competitive recovery of the power stations, working on the basis of renewable energy in comparison with traditional power stations and to solve problems of effective use of power stations of this kind. The obtained conclusions and recommendations provide an essential contribution to the problem resolution of improvement of the habitat of the person, in those regions of Russia where forming ecologically more favorable structure of fuel and energy balance on the basis of use of ecologically safe renewable energy resources is possible.

\section{Conclusions}

The main conclusions can be formulated as follows:

1. The authors developed new effective constructive and technical solutions of the power stations, based on RER, which are represented as patents for invention. These technical solutions give the chance to increase efficiency and reliability of power stations'. New technical solution in relation to wind-power units opens a possibility of wider use of wind power stations in areas with average and small wind potential.

2. The methodology of a power-economic viability is developed in order to choose the key parameters of power stations, based on RER.

\section{References}

1. P.P. Bezrukikh, P.P. Strebkov, Renewable energy: strategies, resources, technologies (2005)

2. V.G. Rodionov, Energy. Problems of the present and possibilities of the future (2010)

3. Yu.S. Vasilyev, P.P. Bezrukikh, V.V. Elistratov, Evaluation of renewable energy resourses in Russia (2008)

4. E.A. Volkova, Urban Construction and Architecture 4, 52-56 (2011). doi: 10.17673/Vestnik.2011.04.10.

5. A.N. Starkov, L.B. Landberg, P.P. Bezrukikh, M.M. Borisenko, Wind atlas of Russia (2000)

6. M.M. Borisenko, I.K. Kravchenko, A.N. Prakhov, Climatic resources and methods of its use for applied purposes (2005) 
7. P.P Bezrukikh, V.V. Degtyarev, V.V. Elistratov, E.S. Pantskhava, E.S. Petrov, V.N. Puzakov, G.I. Sidorenko, B.V. Tarnizhevskiy, A.A. Shpak, A.A. Yampolskiy, Reference book on renewable energy reousrces in Russia and local fuel types (2007)

8. V.V. Elistratov, Power stations of low capacity (2005)

9. V.V. Elistratov, Renewable energy (2011)

10. G.I. Sidorenko, G.I. Kudryashova, V.I. Pimenov, Economy of installations of traditional and renewable power resources. Technical and economic analysis (2009)

11. V.V. Elistratov, V.A. Grilikhes, E.S. Aronova, Sun power installations. Evaluation of sun radiation (2008)

12. P.P. Bezrukikh, Technology, economy, ecology (2008)

13. Y.S. Vasiliyev, V.V. Elistratov, Hydropower installation (2011)

14. V.I. Vissarionov and others, Sun energy (2008)

15. M.I. Balzannikov, V.V. Elistratov, Renewable energy resources. Aspects of complex use (2008)

16. M.I. Balzannikov, S.V. Evdokimov, M.V. Ivanov, Hydraulic turbine, Patent No. 2369 770

17. E.I. Alekseyev, M.I. Balzannikov, S.V. Evdokimov, Hydrogeneator of sea currents (Patent No. 2 372 518. req. SSUACE 13.11.2007; pub. 20.05.2009, Bul. № 31.)

18. E.I. Alekseyev, M.I. Balzannikov, S.V. Evdokimov, Rotary wind-power unit with fully rotating blades, Patent No. 2347103.

19. M.I. Balzannikov, S.V. Evdokimov, Yu.M. Galitskova, Wind-power unit Patent Patent No. 2167336.

20. M.I. Balzannikov, S.V. Evdokimov, N.V. Shekhova, Economy and managements of property 1, 68-72 (2015)

21. S.V. Evdokimov, Industrial and civil engineering 8, 35-38 (2010) 